University of Nebraska - Lincoln

DigitalCommons@University of Nebraska - Lincoln

Bureau of Sociological Research - Faculty

Publications

Bureau of Sociological Research (BOSR)

7-1-2007

\title{
Infertility and Life Satisfaction Among Women
}

Julia McQuillan

University of Nebraska - Lincoln, jmcquillan2@Unl.edu

Roselie Torres Stone

University of Nebraska - Lincoln

Arthur L. Greil

Alfred University, New York

Follow this and additional works at: https://digitalcommons.unl.edu/bosrfacpub

Part of the Sociology Commons

McQuillan, Julia; Torres Stone, Roselie; and Greil, Arthur L., "Infertility and Life Satisfaction Among Women" (2007). Bureau of Sociological Research - Faculty Publications. 6.

https://digitalcommons.unl.edu/bosrfacpub/6

This Article is brought to you for free and open access by the Bureau of Sociological Research (BOSR) at DigitalCommons@University of Nebraska - Lincoln. It has been accepted for inclusion in Bureau of Sociological Research - Faculty Publications by an authorized administrator of DigitalCommons@University of Nebraska - Lincoln. 


\title{
Infertility and Life Satisfaction Among Women
}

\author{
Julia McQuillan and Rosalie A. Torres Stone \\ University of Nebraska-Lincoln \\ Arthur L. Greil \\ Alfred University, New York
}

\begin{abstract}
Using data from a random sample of 580 midwestern women, the authors explore the association between lifetime infertility and life satisfaction. Past research shows lower life satisfaction among those seeking help for infertility. The authors find no direct effects of lifetime infertility, regardless of perception of a problem, on life satisfaction; however, there are several conditional effects. Among women who have ever met the criteria for infertility and perceive a fertility problem, life satisfaction is significantly lower for nonmothers and those with higher internal medical locus of control, and the association is weaker for employed women. For women with infertility who do not perceive a problem, motherhood is associated with higher life satisfaction compared to women with no history of infertility.
\end{abstract}

Keywords: infertility, internal medical locus of control, life satisfaction, life course, motherhood

$\mathrm{I}$ s infertility associated with lower life satisfaction among American women? There is reason to think that it might be. It has long been argued that there is a "motherhood mandate" in the United States (Hays, 1998; Russo, 1976), and McMahon (1995) has described in great detail the gendered expectations that push women to become mothers. Although more women are now choosing not to have children (Gillespie, 2003) and although the actual percentage of women having children has recently declined somewhat (Quesnel-Vallee \& Morgan, 2004), the vast majority of American women both expect and desire to have children (Thornton \& Young-DeMarco, 2000). For most American women, motherhood remains a central life goal (Thoits, 1999) 
and a core symbolic experience in adult life (Nock, 1987). Most women rate motherhood as their most important life role (Reitzes \& Mutran, 2003). According to Burton (1998), children are viewed as providing core life meaning, social support, and social integration, as well as instrumental and social assistance in later life.

Conceptualizations of infertility vary across disciplines and studies; therefore, we must first establish how we are using this term. In this study, we use a measure of lifetime infertility. Contrary to demographic use (where infertility means no live births), we use a medical definition of infertility as ever having had an inability to conceive after 12 months of unprotected intercourse (Sciarra, 1994). Our usage is similar to the lay understanding of infertility as a problem in conception and does not imply childlessness. In fact, a large majority of women who have ever had an episode of infertility (our lifetime measure) now have biological children. In addition, we use life satisfaction, subjective well-being, and happiness interchangeably, as do Kohler, Behrman, and Skytthe (2005).

Infertility can therefore be conceptualized as a barrier, even if temporary, to a highly valued goal. Available evidence suggests that life satisfaction is sensitive to blocked goals (Diener \& Diener, 1995; Lucas, Clark, Georgellis, \& Diener, 2004), but it is unclear how long the effects last. Some theorists suggest that individuals have personality-based life satisfaction set points (Headey \& Waring, 1992; Helson, 1947; Kahneman, 1999), but other researchers suggest that life satisfaction can be permanently altered by life events (Diener, Suh, Lucas, \& Smith, 1999; Lucas et al., 2004; Myers, 1992). Research on individuals seeking medical help for infertility shows that higher infertility stress is associated with lower life satisfaction (Abbey, Andrews, \& Halman, 1991). It is unclear if life satisfaction is only lower for those who are currently experiencing infertility or if the effects persist for women who have ever met the criteria for infertility. Because approximately a third of U.S. women have met the criteria for infertility at some point in their lives, this is an important question.

Other questions about the association between infertility and life satisfaction remain. For example, it is unclear if the association will hold for women who do not seek medical help for infertility as it does for those who do seek medical help. This question is important because only about half of those who meet the medical criteria for infertility seek medical help (Chandra \& Stephen, 1998). Not all women who meet the medical criteria for infertility perceive their situation as a problem, but those who do perceive it as a problem are most likely to seek medical help (L. White, McQuillan, Greil, \& Johnson, 2006). It is therefore necessary to ascertain if infertility is associated with life satisfaction for both those who perceive it as a problem 
and those who do not. Few studies separate the consequences of infertility from the consequences of involuntary childlessness. Many women eventually have children or experience secondary infertility; therefore, distinguishing between infertility and involuntary childlessness is useful. Because motherhood has been associated with both higher life satisfaction (Kohler et al., 2005) and lower life satisfaction (Abbey et al., 1991), it is important to assess the separate and combined effects of infertility and motherhood. Diener et al. (1999) suggest that the short- and long-term effects of negative life events on life satisfaction depend on the specific conditions of the event. Life course theory suggests that violating normative cues, such as having children too young or too old or before marrying, should have negative consequences for life satisfaction. We know of no research that specifies if the association between infertility and life satisfaction depends on life course cues (e.g., age or union status). Coping resources can also ameliorate the negative consequences of blocked goals; therefore, it is important to identify if resources (e.g., family income, education, employment status, religiosity, social support, or internal health locus of control) modify the association between infertility and life satisfaction.

The goal of this article is to assess the association between infertility (perceived or not) and life satisfaction. We use a random sample of 580 midwestern women surveyed in 2001. Approximately a third of the sample (196 women) met the medical criteria for infertility at some point in their life, but only 76 say that they have a problem with fertility. Most of the women in the sample are mothers (more than $80 \%$ ), and even more of those who have experienced infertility are mothers (more than $90 \%$ ). Guided by theories about life satisfaction and the life course, we use multiple regression to assess the association between infertility (perceived and not) and life satisfaction, adding measures of motherhood, life course cues, and material and social resources as both direct and modifying effects to answer the questions detailed earlier.

\section{Theoretical Considerations}

\section{Life Satisfaction}

Life satisfaction is the cognitive dimension of subjective well-being (Lucas, Diener, \& Suh, 1996). Several studies have evaluated whether life satisfaction is more of a trait - a relatively stable characteristic of an individual - or more a state varying in response to external circumstances. Those who argue that subjective well-being should be regarded as a trait (Brickman, Coates, \& Janoff-Bulman, 1978; Costa, McCrae, \& Zondeman, 1987; East- 
erlin, 1974; Stones \& Kuzma, 1986) point out that such demographic variables as age, gender, and income account for a small portion of the variance in subjective well-being and that changes in life circumstances affect subjective well-being only moderately (Andrews \& Withey, 1976; Argyle, 1987; Campbell, Converse, \& Rodgers, 1976; Diener et al., 1999; Myers, 1992). Subjective well-being is relatively stable over time (Lucas et al., 2004), with intrapersonal correlations around .35. Most life events affect subjective wellbeing for only 3 months (Suh, Diener, \& Fujita, 1996). According to Diener and Lucas (1999), personality is one of the strongest predictors of subjective well-being.

But to say that subjective well-being is relatively stable is not the same as saying that it is an immutable trait (Veenhoven, 1994). Landua (1992) found that only $10 \%$ of his sample stayed in the same happiness category over time. If intrapersonal correlations are around .35 , that still leaves plenty of room for factors other than personality to play a role in life satisfaction. A large body of research supports the idea that external events and structural variables can affect subjective well-being (Diener et al., 1999; Keyes, 1998; Myers, 2000; Veenhoven, 1994). For example, there are strong relationships between the wealth of nations and mean levels of subjective well-being, and-although the correlations between wealth and subjective well-being are not strongresearch in this area has consistently found significant relationships (Diener \& Oishi, 2000; Veenhoven, 1994). Variables with moderate to strong associations with life satisfaction include education (Campbell et al., 1976), marriage (Glenn, 1975; Gove \& Shinn, 1989), health (Cameron, Titus, Kostin, \& Kostin, 1971; Schultz \& Decker, 1985), and volunteer work (Thoits \& Hewitt, 2001).

One explanation for the relative stability of subjective well-being and greater impact of recent versus distant events on life satisfaction is adaptation (Helson, 1947). Brickman and Campbell (1971) employ the term hedonic treadmill to describe the process by which individuals who experience diminished subjective well-being following a stressful life event gradually return to their baseline (Kahneman, 1999). The idea that individuals return over time to their hedonic set point (Headey \& Waring, 1992) has guided much recent theory and research on subjective well-being (Diener et al., 1999; Lucas et al., 2004; Seligman, 2002). Although adaptive responses to external circumstances are common, they are by no means universal. In a recent study, Lucas et al. (2004) showed that unemployment lowers the set point for life satisfaction. The experience of unemployment results in a diminution of life satisfaction; after unemployment, life satisfaction increases, but it does not return to its previous level. Diener et al. (1999) summarize research that contradicts the hedonic treadmill, arguing that few studies find 
that people completely and rapidly return to a set level of life satisfaction after difficult events. If there is a life satisfaction set point, then women, who have experienced infertility, regardless if they now have a child, should not have different life satisfaction than women who have never experienced infertility. But Diener et al. (1999) argue that deciding if life satisfaction is a trait or state is less important than understanding the conditions under which negative life events affect life satisfaction. One of the central goals of this article is to assess the conditions that make infertility more or less likely to be associated with life satisfaction.

Another plausible explanation for the low associations between life events and life satisfaction is that individuals with more material resources are less reactive to negative life events because they have alternatives (Diener \& Fujita, 1995). In addition to modifying the effects of infertility, emotional coping resources such as religiosity (Ellison, 1991; Gartner, Larson, \& Allen, 1991), internal medical locus of control (Lu, Shih, Lin, \& Ju, 1997), and social support (Lu et al., 1997) should directly contribute to variations in life satisfaction and are likely to modify the infertility to life satisfaction association.

From a sociological perspective, definitions of situations should also contribute to responses to situations. According to Michalos's (1985) multiple discrepancy theory, subjective well-being depends less on one's objective circumstances than it does on a comparison of those circumstances to a number of relative standards. Diener and Fujita (1995) showed that resources are more relevant to subjective well-being when they are more closely related to an individual's goals and aspirations. Therefore, we explore associations between infertility (perceived and not perceived as a problem) and life satisfaction and assess the modifying effects of motherhood and material and social resources.

\section{Life Course}

Life course theory suggests that normative social pressures to have children before a certain age or when married should also be relevant for understanding the association between infertility and life satisfaction (J. M. White $\&$ Kline, 2002). Normative pressure for women to have children persists (Hewlett, 2002), and women feel increasing social pressure to have children as they age and if they marry (McMahon, 1995). Morgan (1982) and Heaton, Jacobson, and Holland (1999) found that older and married women have stronger intentions to have children than younger or unmarried women. Many people realize they face a biomedical barrier only after they attempt to trans- 
late their intent into action. Women who have used contraception to complete education and career goals before having children are often surprised when conception does not occur soon after ceasing contraception (Hewlett, 2002). In some cases, fertility barriers may reinforce determination to have a(nother) child, although others give up on having children (Bulcroft \& Teachman, 2004).

Most research on childlessness examines distress rather than well-being, particularly during older age. The findings on the effects of childlessness are inconclusive. Some studies find little relationship between having no children and distress (Koropeckyj-Cox, 1998; Zhang \& Hayward, 2001), but others find that men and women who were childless because of circumstances showed higher levels of depression than those who were childfree by choice (Connidis \& McMullin, 2002). Nomaguichi and Milkie (2003) find that the effects of having a child on women's depression depend on marital status (more depression for the unmarried, less depression for the married). Evenson and Simon (2005) also demonstrate that no type of parent reports less depression than nonparents but that some types of parents experience more depression than others (e.g., parents with adult children or noncustodial parents). Overall, the research on the consequences of parenthood for depression is inconclusive but does suggest that effects are likely to depend on circumstances. It is unclear how useful research on parenthood and depression is for understanding parenthood and life satisfaction, because motherhood can simultaneously enhance meaning and satisfaction in life but also create more depressive symptoms because of financial and time stressors (McLanahan \& Adams, 1989).

\section{Infertility and Life Satisfaction Research}

Infertility blocks a woman from achieving a highly desired and socially approved goal (e.g., motherhood) and therefore represents a major disruption in most women's projected life course (Greil, 1991; Matthews \& Martin Matthews, 1986; Sandelowski, 1993). Several studies have found that infertility is associated with more psychological distress, particularly for women experiencing involuntary childlessness (Greil, 1997; King, 2003: McQuillan, Greil, White, \& Jacob, 2003; Wright, Allard, Lecours, \& Sabourin, 1989). In general, studies comparing infertile women to noninfertile women have found that infertility has a negative impact on subjective well-being and global life satisfaction (Abbey et al., 1991, 1992; Bromham, Bryce, \& Balmer, 1989; Callan, 1987; Callan \& Hennessey, 1988). Studies of an association between infertility stress and life satisfaction among those seeking help for infertility suggest 
that more infertility stress is associated with lower life satisfaction (Abbey et al., 1991). Compared to mothers, infertile nonmothers report less satisfaction with their lives as a whole and rate life as less interesting, less rewarding, emptier, and lonelier (Callan \& Hennessey, 1988). The variation in stress among those seeking help also suggests that negative consequences from infertility are not uniform but instead are conditioned on other characteristics and circumstances. For example, social support from family, friends, support groups, or therapists can facilitate coping for those who perceive an infertility problem (Hirsch \& Hirsch, 1995).

Most studies, however, have focused on women who are actively seeking medical help for infertility (Greil, 1997). It is estimated that half of women who meet the criteria for infertility seek help. This half is self-selected and likely contains more women with strong desires for a child (Greil \& McQuillan, 2004). It is unclear what the association between infertility and life satisfaction might be among all women meeting the medical criteria for infertility - those who have sought help, those who have not, those who experienced infertility in the past, those who are still experiencing it, those with children, and those without - because this is a heterogeneous group. To assess the role of self-definition on life satisfaction, we separate the women who ever met the criteria for infertility into two categories for these analyses: those who perceived a fertility problem and those who did not. If the definition of the situation is more important than simply experiencing a blocked normative goal, then the effect of infertility on life satisfaction should be stronger among those who perceive a fertility problem. Guided by research on those seeking help or on distress as an outcome as a guide, we expect ever-infertile women to have lower global life satisfaction than women without fertility problems.

It is likely that infertility has different implications for life satisfaction based on life circumstances. Abbey et al. (1994a, 1994b) discovered that achieving parental status enhances global life quality among infertile women. Abbey et al. (1991) reported that, among infertile women, perceived social support leads to improved global well-being. They also found that those with greater internal locus of control enjoy higher levels of well-being. Therefore, we assess the direct and modifying effects of motherhood status, social support, and internal medical locus of control on the infertility to life satisfaction association.

Life course cues that chart normative expectations-for example, being married by one's late $20 \mathrm{~s}$ - should also be associated with life satisfaction and should modify the association of infertility with life satisfaction. Delayed onset of childbearing makes the "biological clock" real for many women, and marriage is still strongly tied to expectations of mother- 
hood (Nock, 1987; Thornton \& Young-DeMarco, 2000). Employment status should also be related to the relationship between infertility and life satisfaction, although it is less clear whether employment will dampen or enhance the desire for motherhood. The combination of increasing years of schooling, older age at marriage, serial marriage patterns (increasing the likelihood that women will marry men who already have their desired number of children; Stewart, 2002), and women's growing career commitment poses challenges to having children at the expected time and should therefore be considered in the equation.

\section{Control Variables}

We also control for several variables that are associated with both infertility and life satisfaction but are not directly implicated by life satisfaction or life course theories. We include an indicator of race/ethnicity, a measure of general health, an indicator of chronic health status, and an indicator of "other fertility." We include "other infertility" as a control variable because the 38 women in this category do not meet the established medical definition of infertility but have medically based barriers to fertility. Because they belong in neither the comparison group nor the focal group, we include them in a separate category and control for them. General health and an indicator of a chronic health condition are also included as control variables because each is associated with fertility status and life satisfaction but do not fit under life course cues or resources.

\section{Specifying the Association Between Infertility and Life Satisfaction}

Few studies exist that address the long-term consequences of infertility on subjective well-being. In the absence of longitudinal data, it is difficult to assess the effect of adaptation to infertility on life satisfaction in a conclusive way. Rather, we examine several unresolved questions that we can fruitfully explore with our data. In this article, we evaluate the effects of a blocked but normatively central life goal-lifetime experience of infertility - on life satisfaction among a random sample of midwestern U.S. women. We compare the effect of infertility among the infertile who do and who do not perceive themselves as having a fertility problem and among those who do and do not eventually have a child. We also assess the modifying effects of coping and material resources. The following hypotheses/ expectations were derived from life satisfaction theory, life course theory, and past research on infertility and life satisfaction. We control for race/ethnicity, general health, chronic health conditions, and other infertility when evaluating these hypotheses: 
Hypothesis 1: Women who have ever met the criteria for infertility should have lower life satisfaction than women who have never met the criteria for infertility.

Hypothesis 2: The difference between women with a fertility problem and women without a fertility problem should be larger for the subgroup of women who also perceive a fertility problem.

Hypothesis 3: Among all women, mothers should have higher life satisfaction than nonmothers. Hypothesis 4: Controlling for motherhood should at least partially mediate the association between infertility and life satisfaction.

Hypothesis 5: The difference in life satisfaction between women with an infertility history and women without an infertility history should persist when life course cues and material and social resources are included in the model.

Hypothesis 6: Motherhood, life course cues, and material/social resources should modify the association between infertility and life satisfaction. Specifically:

Hypothesis $6 a$ : Women who meet the criteria for infertility and are mothers should have life satisfaction scores that are closer to women without an infertility history than women who meet the criteria for infertility but are not mothers.

Hypothesis 6b: Motherhood cues (being in a union or being older) should make the difference in life satisfaction scores larger between women with and without a history of infertility.

Hypothesis 6c: More material resources (employment, education, family income) and more social resources (social support, internal health locus of control and religiosity) should mitigate the difference in life satisfaction scores between women with an infertility history and women without an infertility history.

\section{Method}

Sample

Our data consisted of a random sample of U.S. women ages 25 to 50 with an oversample of women in high minority (Black and Hispanic) census tracts. Women from 12 states in the upper Midwest participated in the study (Iowa, Illinois, Indiana, Kansas, Michigan, Minnesota, Missouri, North Dakota, Nebraska, Ohio, South Dakota, and Wisconsin). Study participants were selected via random digit dialing. Interviews took place over the telephone using computer-assisted telephone interviews. The interviews were conducted in the spring of 2002 by the Bureau of Sociological Research of the University of Nebraska-Lincoln. The mean length of interviews overall was 36 min. The 
structured interview included measures of background characteristics, fertility status, pregnancy history, help-seeking behavior, and social psychological outcomes.

The overall response rate was $63 \%$, but the rate of cooperation among contacted households was $78 \%$. Comparison with Census data for the 12 states showed that the average age (38 years) of the sample closely mirrored the general population. As intended, the sample overrepresented African Americans: $15 \%$ of the sample is African American compared to $10 \%$ of women ages 25 to 50 in these states. As is usual with telephone surveys, the sample overrepresented well-educated women: $36 \%$ of the sample compared to $27 \%$ in the census reported 4-year college degrees, limiting generalizability to areas beyond the Midwest and to less educated women.

\section{Measures}

The criterion variable in this study is life satisfaction. We used a scale created by Diener and Diener (1995) that has desirable psychometric properties across a variety of ages to measure life satisfaction. Respondents were asked whether they strongly agreed, agreed, disagreed, or strongly disagreed with the following statements: "In most ways, my life is close to ideal; I am satisfied with my life; if I could live my life over, I would change almost nothing; so far, I have gotten the important things I want in life." This unidimensional scale was created by taking the mean of these items (alpha $=.75$ ).

To examine the effect of infertility on life satisfaction, it is necessary to classify the women in our sample according to fecundity status. Women are regarded as subfecund if they report one of three situations: They tried unsuccessfully to get pregnant for 1 year or more, they tried for 12 months or more to conceive any of their pregnancies, or they had 1 year or more of unprotected intercourse without pregnancy. It should be noted that women were asked if they ever experienced one of these situations; therefore, this is a lifetime measure. Women are classified as infertile if they have ever experienced a period in their lives when they fit the medical definition of infertility. Of the 580 women who were interviewed, 196 (34\%) met the criteria for infertility at some point in their life. For some women, the period of time that qualifies them as infertile occurred many years in the past. Therefore, this is a conservative test of the effect of infertility on life satisfaction.

Of these 196 women, 69 women $(35 \%)$ who answered "yes" to the question, "Do you think of yourself as someone who has or has had fertility problems?" are coded 1 on perceive a problem. The remaining 127 women are coded 0 because they answered "no" to the same question. All 196 infertile 
women consider at least one child ideal for them; therefore, none of these women are voluntarily childless.

The "other fertility problems" category includes 38 women who do not fit medical definitions of infertility but who encountered fertility problems that make us hesitant to classify them as not infertile. These women reported a wide variety of problems: Their own or their partner's surgical sterilization (including voluntary sterilizations) definitely kept them from having children that they wanted, their doctor advised them not to have more children even though they wanted more ( 9 women who had a baby despite their doctor's advice are not counted here), and they felt that difficulty getting pregnant definitely kept them from having babies they wanted (although they met none of the criteria established for medically defined infertility). In a larger sample with more detailed information, each of these could be examined separately and more extensively. Rather than exclude these women from the analysis, we coded them as one category and included this as a control variable in the analyses.

A woman is considered to be a mother if she has borne at least one child, is close to at least one stepchild, has adopted at least one child, has raised any children as her own (informal foster care), or some combination of the above. Of the 504 women who are parents, 474 have biological children. Preliminary analyses showed no differences between the biological and nonbiological mothers; therefore, we collapsed these categories into the category "mother."

\section{Life Course Cues (Relationship Status and Age)}

Relationship status was assessed based on answers to the question, "What is your current marital status? Are you currently married, divorced, widowed, separated, or never married?" Dummy variables for married and for cohabiting were included in the analysis and compared to single, divorced, and widowed. Age is assessed via the question, "How old were you on your last birthday?" Age and marriage are normative triggers to childbearing; employment status may suggest an alternative life path than motherhood.

\section{Resources (Education, Family Income, Employment Status, Internal Health Locus of Control, Religiosity)}

Material coping resources were measured by education and family income. Education in years is determined by answers to the question, "How many years of schooling have you completed?" Total family income was recorded in 13 categories ranging from 0 (no income) to 12 (\$100,000 or more). We use dollar equivalents of the midpoint of each category, reported 
in $\$ 10,000$ s to make the coefficients easier to read. The Expectation Maximization imputation procedure in SPSS imputed values for 40 cases $(7 \%)$ with missing data on income. Employment status was measured by a dummy variable (full-time or part-time $=1$ ) gleaned from answers to the query, "I'd like to know a little bit about your present job. Last week you were employed full-time, part-time, going to school, keeping house, or something else?" Social coping resources were measured by social support, internal health locus of control, and religiosity. Social support is measured by an averaged 8-item scale designed to tap medically relevant social support (Sherbourne \& Stewart, 1991). Respondents were asked how often various forms of social support (e.g., someone to give you good advice about a crisis, someone to share your most private worries and fears with) were available when they needed it. Answers ranged from $4=$ often to $1=$ never. The single factor scale has an alpha of .93. Health locus of control consists of five of the six items from the Internal Health Locus of Control Scale (Wallston, Wallston, \& DeVellis, 1978), designed to measure the extent to which individuals believe that they can influence their own health outcomes. A higher score denotes greater internal control. It is measured as the mean of five items, reversed, provided in a strongly agree (1) to strongly disagree (4) format: "If I get sick, it is my own behavior which determines how soon I get well again; I am in control of my own health; When I get sick, I am to blame; If I take care of myself, I can avoid illness; If I take the right actions, I can stay healthy" $(\alpha=.65$ among the infertile).

Religiosity was measured by a three-item scale $(\alpha=.78)$ that averages responses to the following Likert-type items: "In general, how much would you say your religious beliefs influence your daily life? About how often do you pray? How close do you feel to God most of the time?" Higher scores indicate greater religiosity.

\section{Control Variables (Race/Ethnicity, General Health, Chronic Health Condition)}

Because of the small sample size, we use a coarse measure of race/ ethnicity: A dummy variable identifies women who were not non-Hispanic White. General health was determined by responses to the question, "In general, would you say your health is excellent, good, fair, or poor?" This variable is coded so that a higher number reflects a higher (better) self-reported health status. Despite the simplicity of this measure, it is a highly reliable indicator of health. Chronic health problem is based on answers to the question "Do you have any chronic health problems?" "Yes" is coded as 1 . Other infertility was described above. 


\section{Analysis}

Figure 1 portrays the expected relationships between the variables in the analyses. In addition to direct effects of all of the variables, motherhood is expected to mediate the effects of infertility, and life course cues and resources are expected to modify the association between infertility and life satisfaction. We analyze our data by means of ordinary least squares multiple regression using SPSS. We enter variables in four blocks. In the first block, we regressed life satisfaction on infertility status (with and without perception), controlling for race/ethnicity, general health, chronic health condition, and other infertility. The second block adds motherhood status to assess whether the life satisfaction to infertility relationship is mediated by motherhood. The third block includes life course cues and resources to the analyses. The final model includes the statistically significant interaction terms that emerged after separately running interactions by infertility (with and without perception of a problem) and motherhood status plus each of the life course cues and resource variables.

\section{Results}

Table 1 presents descriptive statistics by fertility status. Hypothesis 1 posited that infertile women would exhibit lower levels of life satisfaction. Because there are no significant differences between the three fertility groups, there appears to be little support for Hypothesis 1 . As predicted by Hypothesis 2, mean life satisfaction is highest among those with no infertility history and lowest among women who have ever experienced infertility and perceived a fertility problem, but the differences are not significant. As the multivariate analysis will show, the situation is somewhat more complicated than these bivariate results suggest. A significantly higher proportion of women with an infertility history are mothers compared to those with no fertility problem. This is not as surprising as it might seem at first glance, because most infertility is secondary infertility, because approximately half of involuntarily childless couples eventually have children, and because those who have not attempted to have children are not counted as infertile (Abma, Chandra, Mosher, Peterson, \& Piccinino, 1997; Chandra \& Stephen, 1998).

Table 1 also shows that a substantially and significantly higher percentage of married women are in the "perceive an infertility problem" or no infertility group than in the "no perceive an infertility problem" group. This finding suggests that married women are more likely to perceive infertility as a problem, 


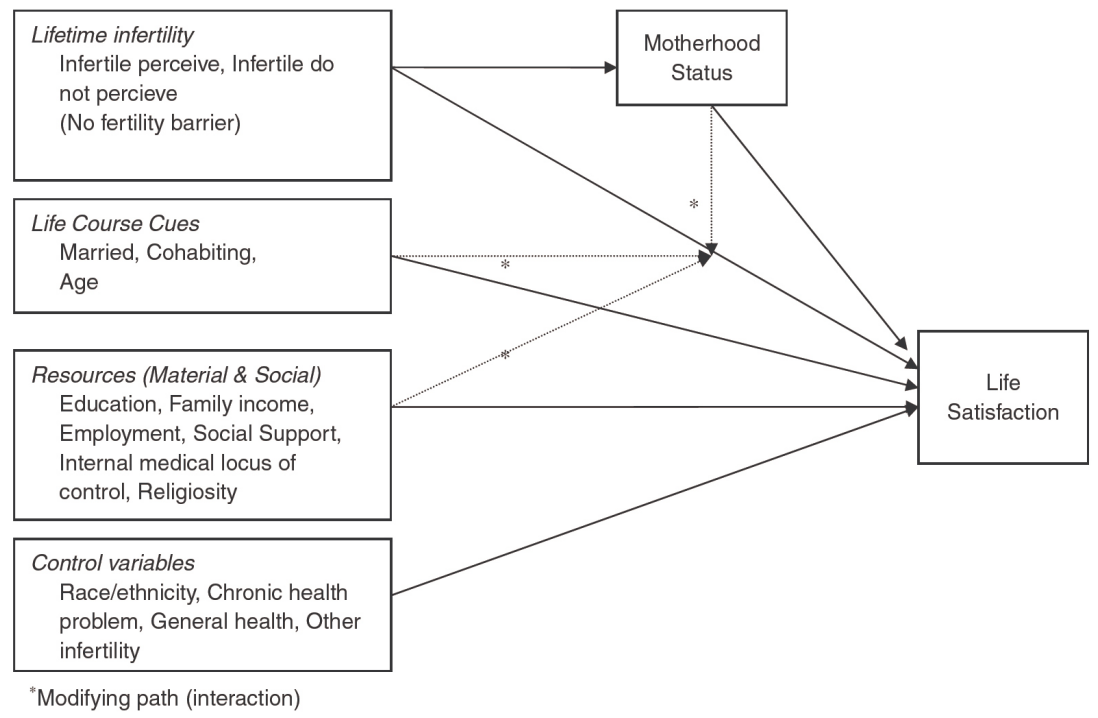

Figure 1. Conceptual Framework for the Effect of Lifetime Infertility on Life Satisfaction

and it lends support to the idea that marriage is a cue to motherhood. Married women may be more likely than unmarried women to want to be mothers and thus may be more likely to perceive not conceiving as a problem. The only resource that differs between the three groups is education. Those with no infertility history have the highest average education. This finding is somewhat surprising because some authors assume that more women are experiencing infertility problems because of delaying motherhood for education (Hewlett, 2002). The two health-related control variables also differ significantly between the groups. Significantly more women who perceive an infertility problem also report a chronic health problem than women without an infertility history or who do not perceive a problem. Women who perceive a problem have the lowest and women with no infertility history have the highest average general health.

Table 2 presents the multiple regression results. The coefficients for the "infertility, no perception" and "infertility, perceive" dummy variables represent possible gaps in life satisfaction compared to women with no infertil- 
Table 1. Descriptive Statistics by Infertility Status

\begin{tabular}{|c|c|c|c|c|c|c|c|c|c|}
\hline & \multicolumn{3}{|c|}{$\begin{array}{l}\text { No Infertility } \\
\quad(n=345)\end{array}$} & \multicolumn{3}{|c|}{$\begin{array}{c}\text { Infertile } \\
\text { Perceive a } \\
\text { Problem }(n=69)\end{array}$} & \multicolumn{3}{|c|}{$\begin{array}{c}\text { Infertile } \\
\text { Do Not Perceive a } \\
\text { Problem }(n=127)\end{array}$} \\
\hline & $M$ & $S D$ & $\%$ & $M$ & $S D$ & $\%$ & $M$ & $S D$ & $\%$ \\
\hline Global Life Satisfaction & 3.01 & 0.43 & & 2.90 & 0.48 & & 2.97 & 0.51 & \\
\hline \multicolumn{10}{|l|}{ Motherhood status } \\
\hline Mother* ${ }^{\mathrm{a}}$ & & & 83 & & & 0.87 & & & 94 \\
\hline \multicolumn{10}{|l|}{ Life course cues } \\
\hline Married $^{*}{ }^{\mathrm{b}}$ & & & 66 & & & 0.84 & & & 67 \\
\hline Cohabiting & & & 07 & & & 0.03 & & & 06 \\
\hline Age in years & 38.13 & 6.94 & & 39.06 & 6.29 & & 38.51 & 7.14 & \\
\hline \multicolumn{10}{|l|}{ Resources } \\
\hline Education $\left(\right.$ years) ${ }^{* *^{c}}$ & 14.76 & 2.48 & & 14.39 & 2.25 & & 13.85 & 2.18 & \\
\hline Family income $(\times \$ 100 \mathrm{k})$ & 5.88 & 2.74 & & 6.17 & 2.41 & & 5.32 & 2.47 & \\
\hline Employee & & & 81 & & & 0.83 & & & 74 \\
\hline Social support & 3.72 & 0.45 & & 3.67 & 0.56 & & 3.63 & 0.53 & \\
\hline $\begin{array}{l}\text { Internal medical locus } \\
\text { of control }\end{array}$ & 2.84 & 0.38 & & 2.73 & 0.38 & & 2.84 & 0.42 & \\
\hline Religiosity & 4.33 & 0.96 & & 4.61 & 0.72 & & 4.39 & 1.06 & \\
\hline \multicolumn{10}{|l|}{ Control variables } \\
\hline White, non-Hispanic & & & 81 & & & 0.77 & & & 71 \\
\hline Chronic health problem* & & & 17 & & & 0.38 & & & 20 \\
\hline General health $* *^{\mathrm{d}}$ & 3.28 & 0.68 & & 2.90 & 0.88 & & 3.10 & 0.70 & \\
\hline
\end{tabular}

a. "Do not perceive a problem" differs significantly from no infertility history and "perceive a problem."

b. "Perceive of problem" differs significantly from no infertility history and "do not perceive a problem."

c. "Do not perceive a problem" differs significantly from no infertility history.

d. "Perceive a problem" differs significantly from no infertility history. ${ }^{*} p<.05 .{ }^{* *} p<.01$ (Scheffe post hoc test).

ity history. In each model, the constant represents those in the omitted categories on the dummy variables and with the mean values on the continuous variables. For example, in Model 1, the constant indicates the mean life satisfaction for women with no history of infertility, who are non-White, who do not have a chronic health problem, and who have average self-reported health. Model 1 also shows that the differences in average life satisfaction between those with a history of infertility (with and without perception of a 
problem) and those without (represented by the constant) are small and not significant. Contrary to what the bivariate results show, minority status is associated with lower life satisfaction in this multivariate model. In Model 2 , we added a dummy variable for "mother." Model 2 of Table 2 provides support for Hypothesis 3; mothers have significantly higher life satisfaction than nonmothers $(B=.14)$. Because this model controls for infertility, health, and minority status, the coefficient compares mothers to nonmothers who have no history of infertility. The motherhood coefficient represents about a third of a standard deviation increase in life satisfaction $(.14 / .46=$ .30). Hypotheses 4 and 5, which depend on an association between infertility and life satisfaction, had no chance of support because of the lack of such an association.

Before discussing Hypothesis 6, we summarize the associations between the life course cue variables, resource variables, and life satisfaction in Model 3 of Table 2. Several of the life course and resource measures have significant associations with life satisfaction. Women who are married have significantly higher life satisfaction than women who are not married, increasing years of education is associated with more life satisfaction, and increases in social support, internal health locus of control, and religiosity are all associated with higher life satisfaction. It appears that the motherhood association is spurious because it is no longer significant when the life course cues and resources variables are included in the model.

The three parts of Hypothesis 6 focus on the modifying effects of motherhood, life course cues, and resources on the associations between infertility (with and without perception) and life satisfaction. Model 4 of Table 2 shows that motherhood modifies the gap in life satisfaction between women who have a history of infertility and women who do not have a history of infertility. Among women who perceive a problem, the gap coefficient is now substantial $(-.63 / .43=1.46$ standard deviations $)$ and significant for women who are not mothers. Average life satisfaction for women who are not mothers and have no infertility problems, controlling for all of the other variables in the model, is 2.96 (the constant). Women with a history of infertility but do not perceive it as a problem and are not mothers is -.26 lower

(2.70) and for those who are mothers, is $.01+.36$ higher (3.07). Women who have ever experienced infertility and perceive a problem and are mothers have higher life satisfaction than women with no history of infertility, but the difference in life satisfaction is only significant for women who did not perceive an infertility problem. The gap in life satisfaction between women who perceive infertility as a problem and those with no history of infertility is significant and negative for women who are not mothers. As anticipated in Hypothesis $6 \mathrm{a}$, the "infertility gap" in life satisfaction depends on motherhood 


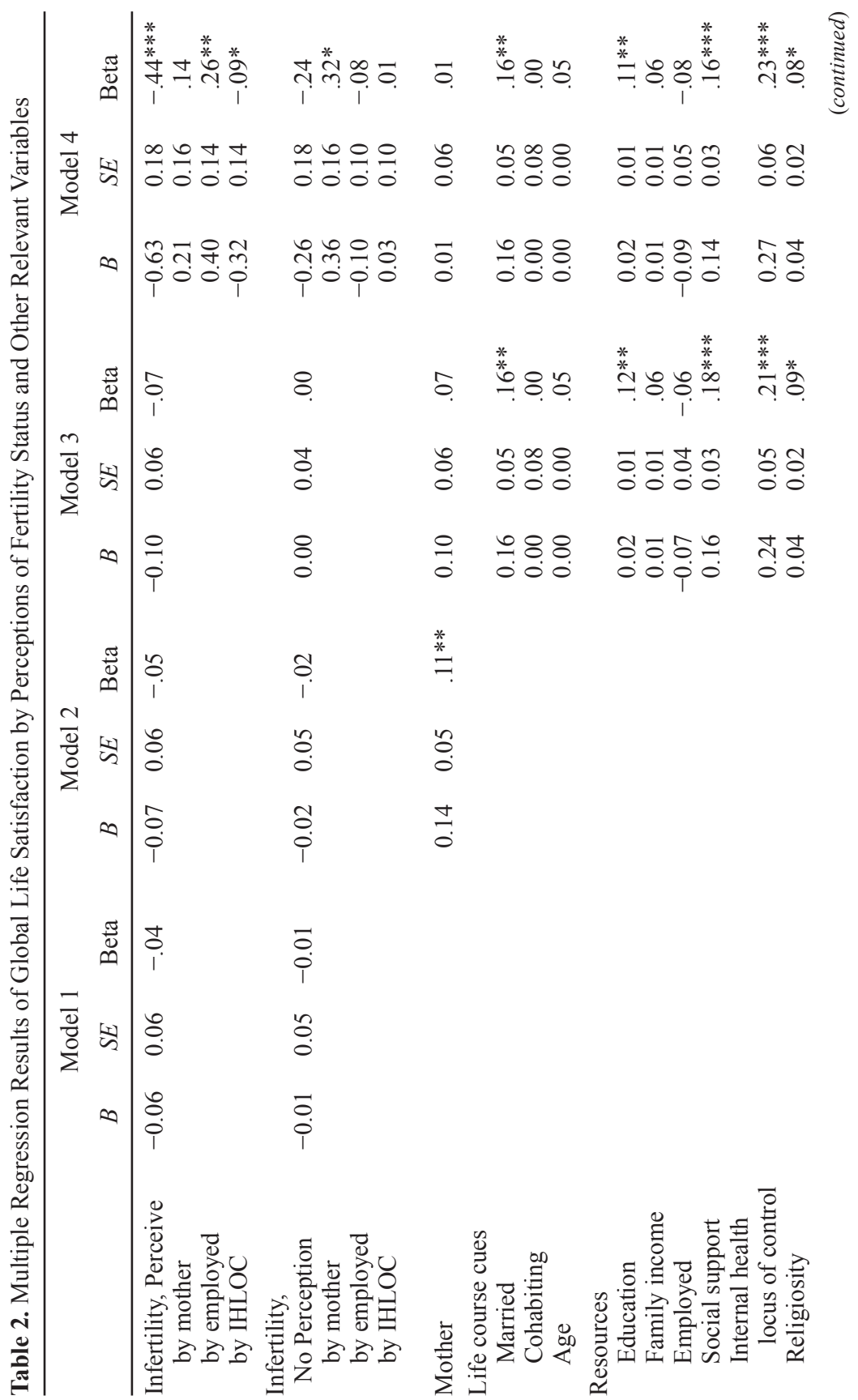




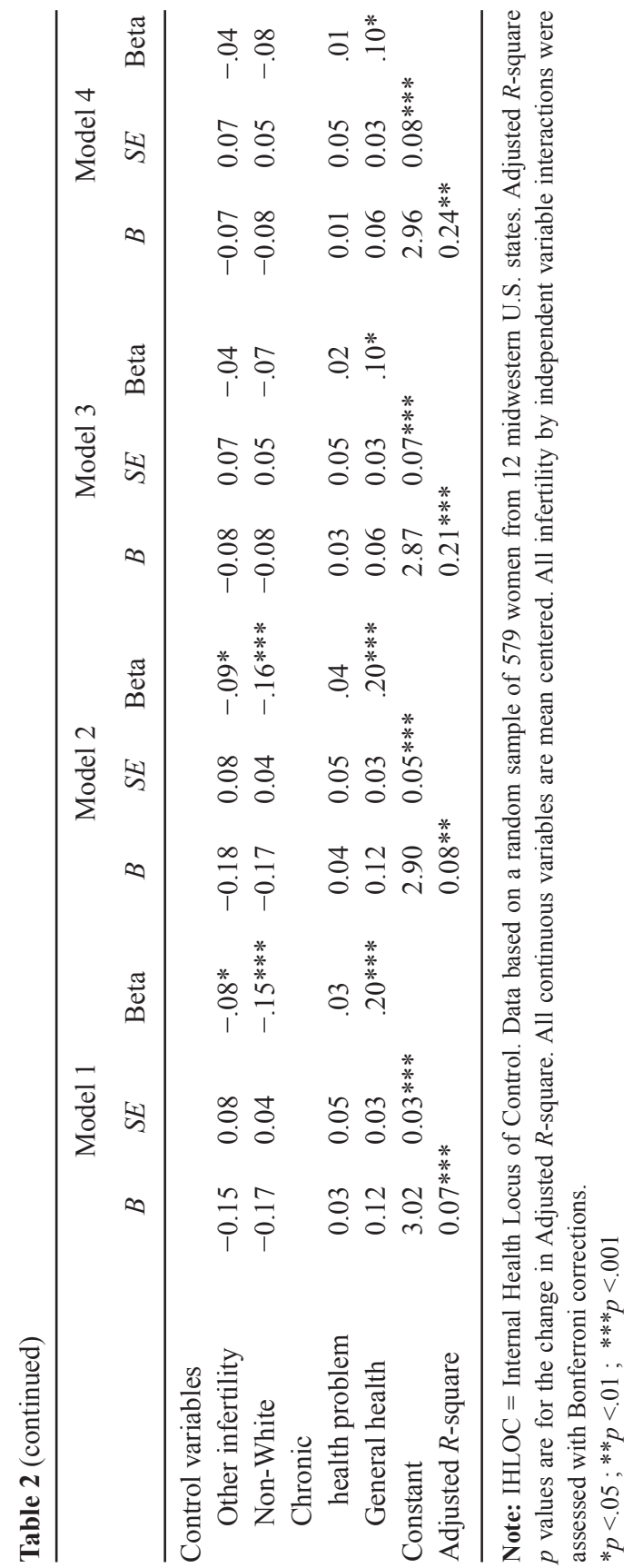


status. None of the life course cue measures (married, age, or union status) evidenced a significant interaction with infertility; thus, Hypothesis $6 \mathrm{~b}$ was not supported.

There is more support for the modifying effects of resources. Two resource measures, being employed and internal health locus of control, significantly modify the infertility life satisfaction gaps. Employment ameliorates the negative effects of infertility by approximately a quarter $(-.63+.40=-.23)$ and represents almost a standard deviation in the Life Satisfaction Scale $(.40 / .46=$ $87 \%$ ). Increasing internal locus of control exacerbates the negative effects of infertility perceived as a problem by -.32 for each unit increase. This also represents a substantial decrease in life satisfaction $(70 \%$ of a standard deviation for each unit increase). These results provide partial support for Hypothesis $6 \mathrm{c}$, that resources should mitigate the consequences of infertility.

It is when modifying effects are added to the model that the relationship between infertility, self-definition, and life satisfaction becomes clear. The infertility perceived as a problem coefficient now represents the association for women in this category who are also unemployed and not mothers. The coefficient is now statistically significant and substantial $(B=-.63$, or about 1.5 $S D$ s). It is interesting that employment ameliorates the strong negative association between infertility (compared to no infertility) and life satisfaction for nonmothers. The association is two thirds as large $(-.63-.40=.23$, or .23/$.63=.37$ ) for women who are employed. The association is large and significant, but in our sample, only three women are infertile unemployed nonmothers who perceive a problem and six are in the same categories but employed. This finding is tentative because it is based on a small group of women; the finding is nonetheless robust and interesting.

The pattern is quite different for women who meet the criteria for infertility but do not perceive a fertility problem. For them, unemployment and not being a mother is not associated with significantly lower life satisfaction (although the coefficient is now much larger, -.26), but motherhood is associated with a large increase in life satisfaction $(B=.36$, or almost a standard deviation). The strong negative association between internal health locus of control and life satisfaction that exists for the infertile who perceive a problem is almost 0 in the group who do not perceive a problem. The associations for the remaining theoretical and control variables did not change.

\section{Conclusion and Discussion}

We examined six hypotheses regarding the association between infertility and life satisfaction derived from life satisfaction theory, life course the- 
ory, and past empirical research. We expected that women with a history of infertility would have lower life satisfaction than women who have never experienced infertility, but this bivariate association did not emerge. This finding suggests that infertility may not have persistent effects beyond the period of unprotected intercourse without conception. We also expected, but did not find, that the gap in life satisfaction between women with and women without a fertility problem would be even larger for the subgroup of women who also perceived an infertility problem. But, as we discuss below, there are several conditional effects.

Because a more rigorous and more recent study (using a twin comparison approach) found a positive association between motherhood and life satisfaction (Kohler et al., 2005), we expected the same. We did find that mothers have higher life satisfaction than nonmothers when we controlled for fertility status, minority status, and health. This association, however, appears spurious when we control for life course cues and resources. There is a strong association between motherhood and marriage $(r=.30, p<.001)$, and the association between marriage and life satisfaction persists in the final model. Therefore, the apparent association between motherhood and life satisfaction is actually created by shared associations with marriage. Rather than marriage being primarily a cue for motherhood, we find that marriage is more directly associated with life satisfaction than either motherhood or infertility. With cross-sectional data, it is impossible to assess if women with more general life satisfaction are more likely to be married, but this causal order is also plausible.

Our fourth and fifth hypotheses presumed that women with an infertility history would have significantly lower life satisfaction than women without an infertility history, but this was not the case. Therefore, motherhood, life course cues, and resources could not mediate the association. It is likely that heterogeneity among women in the infertility categories contributed to the lack of direct association between lifetime infertility and life satisfaction. For example, among the infertile in this sample, fewer than 50\% experienced infertility in the past 10 years, about half never sought any medical advice or help for infertility, many are mothers, and the average age is 39 . Compared to more homogeneity among those seeking medical help (more educated and more wealthy; Jain \& Hornstein, 2005), the heterogeneity among the random sample of women who meet the criteria for infertility likely dilutes the association. As we discuss later, an association between infertility and life satisfaction emerges for certain groups of women.

Researchers studying the ability of individuals to adapt to negative life events debate whether the evidence supports a more "trait-like" or a more 
"state-like" conceptualization of life satisfaction. Overall stability or an ability to return to a "set point" via a "hedonic treadmill" suggests that life satisfaction is more of a trait and that personality is one of the strongest predictors of subjective well-being (Diener \& Lucas, 1999). Evidence of changes in life satisfaction consistent with negative and positive life events supports a more state-like conceptualization of life satisfaction (Lucas et al., 2004; Myers, 2000). Because of considerable evidence that life satisfaction changes over time, Diener et al. (1999) argue that attention should focus on understanding the conditions under which adaptation does and does not occur, rather than pushing for a single conceptualization. The three parts of Hypothesis 6 focus on identifying the conditions under which women who experience a blocked normatively central life goal-lifetime infertility - have lower life satisfaction than women who have not experienced infertility. We found the relationship between infertility and life satisfaction to be complex. Unlike spells of unemployment (Lucas et al., 2004), simply having experienced infertility does not have long-term consequences for life satisfaction.

But under certain conditions, women who have experienced infertility do have significantly lower life satisfaction than women who have not experienced infertility. Women who meet the criteria for infertility but do not perceive a fertility problem have significantly lower life satisfaction if they are not mothers and significantly higher life satisfaction if they are mothers (compared to women with no infertility history). Women who meet the criteria for infertility and perceive infertility as a problem have higher life satisfaction if they are employed (compared to women with no infertility history). In addition, the association between internal health locus of control and life satisfaction is negative and significant for women who perceive their infertility as a problem.

Our findings reveal that, compared to women with no infertility history, life satisfaction is significantly lower for women who perceive a problem and are currently blocked from motherhood but not for those who became mothers. Therefore, motherhood seems to mean something different for women who have experienced infertility as a problem, for women who have not experienced infertility as a problem, and for women who have not experienced infertility. Employment status and internal health locus of control significantly modify the association of infertility with perception of a problem but not infertility without perception of a problem and life satisfaction. Employment may also take on different meaning for women who experience a delay in conceiving a child, particularly if that delay is considered a problem. Marriage has a strong association with life satisfaction for all of the women in the sample, but employment is only associated with higher life satisfaction 
for women who perceive a fertility problem. Both social roles (employee and spouse) have strong associations with depressive symptoms (Mirowsky \& Ross, 2003), but we find that only marriage has a consistently strong association with life satisfaction. These findings suggest that the definition of the situation is important for understanding the association between infertility and life satisfaction.

The fact that internal health locus of control is associated with life satisfaction for the subfecund who perceive a problem but not for the subfecund who do not perceive a problem may also be related to differences in how women interpret their situation. As Michalos's (1985) multiple discrepancy theory posits, subjective well-being depends less on one's objective circumstances than it does on a comparison of those circumstances to a number of relative standards. Perhaps subfecund women who perceive a problem and who have a high internal health locus of control feel responsible for their condition and have lower life satisfaction for this reason. For women who do not perceive themselves as having a problem, feeling responsible for one's own health may be less of an issue.

Does motherhood alter the experience of infertility? Our results help to specify the conditions under which this occurs. The infertile who perceive a problem and have no children experience significantly lower life satisfaction than women with no history of infertility, but the gap in life satisfaction does not emerge for women who do not perceive a problem and have no children. This indicates that meeting the medical criteria for infertility alone is not the primary issue. Rather, it is perceiving a problem and failing to achieve biological motherhood that matters most for life satisfaction. Objective life circumstances have a greater impact on life satisfaction when not meeting the goal is perceived as a problem.

Because the infertile who do not perceive a problem also tend to not seek medical help for infertility (L. White et al., 2006), it is unlikely that this group suffers as much from lower life satisfaction as the help seekers do. In addition, unlike those in previous studies who lost jobs and then got new ones, these results suggest that being prevented from achieving a highly valued life goal does not necessarily lower the set point for life satisfaction. Eventually having a desired child is associated with higher life satisfaction compared to those who never have a child. Only two resource variables modified the association between infertility (perceived) and life satisfaction. We expected that income and education would have more of a modifying effect because of recent reports of professional women suffering from infertility (Hewlett, 2002). Our overall results suggest few long-term consequences of having experienced infertility. Instead, persistent involuntary childlessness is associated with lower life satisfaction for women who perceive infertility as a problem. It is even 
more damaging to life satisfaction for women who believe that they should be able to control their health but is somewhat ameliorated by employment.

It is interesting that life course cues (union status and age) did not modify the association between infertility and life satisfaction. It is possible that longitudinal research would reveal more of an impact of normative expectations on the experience of infertility. Because our measure is of lifetime infertility, it is possible that the "episode" of extended unprotected intercourse without conception occurred when the women in this sample were not in a union or when they were much younger. Our inability to match age and union status with the occurrence of the infertility period is an important limitation that should be addressed with longitudinal research. Life satisfaction research presumes that blocked goals lead to lower life satisfaction, but without longitudinal data, we cannot establish causal order with certainty. We are currently in the process of collecting the longitudinal data that will provide this information.

A practical implication of this research is that helping women achieve motherhood, if desired, is an important goal for maintaining or increasing life satisfaction. Another possible practical implication is that if we lower the centrality or importance of motherhood, women can also maintain high levels of life satisfaction when they experience infertility. Gillespie (2003) provides evidence of women who are redefining the meaning of femininity separate from motherhood and creating fulfilling lives. Thornton and Young-DeMarco (2000) provide evidence from several surveys that more women are choosing to be childfree. Within the infertility research paradigm, this latter option is less discussed than it is within the feminist family research paradigm, but both strategies are consistent with our findings.

\section{Acknowledgments}

The University of Nebraska-Lincoln provided essential funding for this project. Lynn White gave critically important suggestions and insights. The remaining members of the Family Life Research Team (David Johnson, Laurie Scheuble, Naomi Lacey, and Casey Jacobs) all contributed to making this project possible.

\section{References}

Abbey, A., Andrews, F. M., \& Halman, L. J. (1991). The importance of social relationships for infertile couples' well-being. In A. L. Stanton \& C. A. Dunkel Schetter (Eds.), Infertility: Perspectives from stress and coping research (pp. 11-86). New York: Plenum.

Abbey, A., Andrews, F. M., \& Halman, L. J. (1992). Infertility and subjective well-being: The mediating roles of self-esteem, internal control, and interpersonal conflict. Journal of Marriage and Family, 54, 408-417. 
Abbey, A., Andrews, F. M., \& Halman, L. J. (1994a). Psychosocial predictors of life quality: How are they affected by infertility, gender, and parenthood? Journal of Family Issues, 15, 253-271.

Abbey, A., Andrews, F. M., \& Halman, L. J. (1994b). Infertility and parenthood: Does becoming a parent increase well-being? Journal of Consulting and Clinical Psychology, 62, 398-403.

Abma, J., Chandra, A., Mosher, W., Peterson, L., \& Piccinino, L. (1997). Fertility, family planning, and women's health: New data from the 1995 national survey of family growth. U.S. National Center for Health Statistics. Vital and Health Statistics, 23(19), 1-114.

Andrews, F. M., \& Withey, S. B. (1976). Social indicators of well-being. New York: Plenum. Argyle, M. (1987). The psychology of happiness. London: Routledge.

Brickman, P., \& Campbell, D. T. (1971). Hedonic relativism and planning the good society. In M. H. Appley (Ed.), Adaptation-level theory (pp. 287-305). New York: Academic Press.

Brickman, P., Coates, D., \& Janoff-Bulman, R. (1978). Lottery winners and accident victims: Is happiness relative? Journal of Personality and Social Psychology, 36, 917-927.

Bromham, D. R., Bryce, F. C., \& Balmer, B. (1989). Psychometric evaluation of infertile couples. Journal of Reproductive and Infant Psychology, 7, 195-202.

Bulcroft, R., \& Teachman, J. (2004). Ambiguous constructions: Development of a childless or childfree life course. In M. Coleman \& L. H. Ganong (Eds.), Handbook of contemporary families (pp. 116-135). Thousand Oaks, CA: Sage.

Burton, R. (1998). Global integrative meaning as a mediating factor in the relationship between social roles and psychological distress. Journal of Health and Social Behavior, 39, 201-215.

Callan, V. J. (1987). The personal and marital adjustment of mothers and of voluntarily and involuntarily childless wives. Journal of Marriage and Family, 49, 847-856.

Callan, V. J., \& Hennessey, J. F. (1988). The psychological adjustment of women experiencing infertility. British Journal of Medical Psychology, 61, 137-140.

Cameron, P., Titus, D. G., Kostin, J., \& Kostin, M. (1971). The life satisfaction of non-normal persons. Journal of Consulting and Clinical Psychology, 41, 207-214.

Campbell, A., Converse, P. E., \& Rodgers, W. L. (1976). The quality of American life. New York: Russell Sage.

Chandra, A., \& Stephen, E. H. (1998). Impaired fecundity in the United States: 1982-1995. Family Planning Perspectives, 30, 34-42.

Connidis, I. A., \& McMullin, J. A. (2002). Sociological ambivalence and family ties: A critical perspective. Journal of Marriage and Family, 64(3), 558-567.

Costa, P. T., McCrae, R. R., \& Zondeman, A. B. (1987). Environmental and dispositional influences on well-being: Longitudinal follow-up of an American national sample. British Journal of Psychology, 78, 299-306.

Diener, E., \& Diener, M. (1995). Factors predicting the subjective well-being of nations. Journal of Personality and Social Psychology, 69, 851-864.

Diener, E., \& Fujita, F. (1995). Resources, personal strivings, and subjective well-being: A nomothetic and idiographic approach. Journal of Personality and Social Psychology, 47, 926-935.

Diener, E., \& Lucas, R. (1999). Personality and subjective well-being. In D. Kahneman, E. Diener, \& N. Schwartz (Eds.), Well-being: The foundations of hedonic psychology (pp. 213229). New York: Russell Sage. 
Diener, E., \& Oishi, S. (2000). Money and happiness: Income and subjective well-being across nations. In E. Diener \& E. M. Suh (Eds.), Culture and subjective well-being (pp. 185-218). Cambridge, MA: MIT Press.

Diener, E., Suh, E. M., Lucas, R. E., \& Smith, H. E. (1999). Subjective well-being: Three decades of progress. Psychological Bulletin, 125, 276-302.

Easterlin, R. A. (1974). Does economic growth improve the human lot? Some empirical evidence. In P. A. David \& M. W. Reder (Eds.), Nations and households in economic growth (pp. 89125). New York: Academic Press.

Ellison, C. G. (1991). Religious involvement and subjective well-being. Journal of Health and Social Behavior, 32, 80-99.

Evenson, R. J., \& Simon, R. W. (2005). Clarifying the relationship between parenthood and depression. Journal of Health and Social Behavior, 46(4), 341-358.

Gartner, J., Larson, D. B., \& Allen, G. D. (1991). Religious commitment and mental health: A review of the empirical literature. Journal of Psychology and Religion, 19, 6-25.

Gillespie, R. (2003). Childfree and feminine: Understanding the gender identity of voluntary childless women. Gender \& Society, 17, 122-136.

Glenn, N. D. (1975). The contribution of marriage to the psychological well-being of males and females. Journal of Marriage and Family Relations, 50, 317-324.

Gove, W. R., \& Shinn, H. (1989). The psychological well-being of widowed and divorced men and women. Journal of Family Issues, 10, 122-144.

Greil, A. L. (1991). Not yet pregnant: Infertile couples in contemporary America. New Brunswick, NJ: Rutgers University Press.

Greil, A. L. (1997). Infertility and psychological distress: A critical view of the literature. Social Science \& Medicine, 45, 1679-1704.

Greil, A. L., \& McQuillan, J. (2004). Help-seeking patterns among U.S. women. Journal of Reproductive and Infant Psychology, 22, 305-319.

Hays, S. (1998). The cultural contradictions of motherhood. New Haven, CT: Yale University Press.

Headey, B., \& Waring, B. (1992). Understanding happiness: A theory of subjective well-being. Melbourne, Australia: Longman Cheshire.

Heaton, T. B., Jacobson, C. K., \& Holland, K. (1999). Persistence and change in decisions to remain childless. Journal of Marriage and Family, 61, 531-539.

Helson, H. (1947). Adaptation-level as frame of reference for prediction of psychophysical data. American Journal of Psychology, 60, 1-29.

Hewlett, S. A. (2002). Creating a life: Professional women and the quest for children. New York: Talk Miramax Books.

Hirsch, A. M., \& Hirsch, S. M. (1995). The long-term psycholosocial effects of infertility. Journal of Obstetrical Gynecological Neonatal Nursing, 24(6), 517-522.

Jain, T., \& Hornstein, M. D. (2005). Disparities in access to infertility services in a state with mandated insurance coverage. Fertility and Sterility, 84, 221-223.

Kahneman, D. (1999). Objective happiness. In D. Kahneman, E. Diener, \& N. Schwartz (Eds.), Well-being: The foundations of hedonic psychology (pp. 3-25). New York: Russell Sage.

Keyes, C. M. (1998). Social well-being. Social Psychology Quarterly, 61, 121-140.

King, R. B. (2003). Infertility and anxiety in a nationally representative sample. Social Science \& Medicine, 56, 739-751. 
Koropeckyj-Cox, T. (1998). Loneliness and depression in middle and old age: Are the childless more vulnerable? Journals of Gerontology B: Psychological Sciences and Social Sciences, 53, S303-S312.

Kohler, H., Behrman, J. R., \& Skytthe, A. (2005). Partner +children = happiness: The effects of partnership and well-being. Population and Development Review, 31, 407-443.

Landua, D. (1992). Satisfaction changes. Social Indicators Research, 26, 221-241.

Lu, L., Shih, J. B., Lin, S. S., \& Ju, L. S. (1997). Personal and environmental correlates of happiness. Personality and Individual Differences, 33, 453-462.

Lucas, R. E., Diener, E., \& Suh, E. M. (1996). Discriminant validity of well-being measures. Journal of Personality and Social Psychology, 71, 616-628.

Lucas, R. E., Clark, A. E., Georgellis, Y., \& Diener, E. (2004). Unemployment alters the set point for life satisfaction. Psychological Science, 15, 8-13.

Matthews, R., \& Martin Matthews, A. (1986). Infertility and involuntary childlessness: The transition to nonparenthood. Journal of Marriage and Family, 48, 641-649.

McLanahan, S., \& Adams, J. (1989). The effects of children on adult's psychological wellbeing: 1957-1976. Social Forces, 68,124-146.

McMahon, M. (1995). Engendering motherhood. New York: Guildford.

McQuillan, J., Greil, A. L., White, L., \& Jacob, M. C. (2003). Frustrated fertility: Infertility and psychological distress among women. Journal of Marriage and Family, 65, 1007-1018.

Michalos, A. C. (1985). Multiple discrepancies theory (MDT). Social indicators Research, 16, 347-413.

Mirowsky, J., \& Ross, C. (2003). Social causes of psychological distress (2nd ed.). New York: Aldine de Gruyter.

Morgan, S. P. (1982). Parity-specific fertility intentions and uncertainty: The United States, 1970 to 1976. Demography, 19, 315-334.

Myers, D. G. (1992). The pursuit of happiness. New York: William Morrow.

Myers, D. G. (2000). The funds, friends, and faith of happy people. American Psychologist, 55, $56-67$.

Nock, S. L. (1987). The symbolic meaning of childbearing. Journal of Family Issues, 8, 373-393.

Nomaguichi, K. M., \& Milkie, M. A. (2003). Costs and rewards of children: The effects of becoming a parent on adults' lives. Journal of Marriage and Family, 65, 356-374.

Quesnel-Vallee, A., \& Morgan, S. P. (2004). Missing the target: Correspondence of fertility intentions and behavior in the U.S. Population Research and Policy Review, 22, 497-525.

Reitzes, D. C., \& Mutran, E. J. (2003). Self concept as the organization of roles: Importance, centrality, and balance. Sociological Quarterly, 43, 647-667.

Russo, N. F. (1976). The motherhood mandate. Journal of Social Issues, 32, 143-157.

Sandelowski, M. (1993). With child in mind: Studies of the personal encounter with infertility. Philadelphia: University of Pennsylvania Press.

Schultz, B., \& Decker, S. (1985). Long term adjustment to physical disability. Journal of Personality and Social Psychology, 48, 1162-1172.

Sciarra, J. (1994). Infertility: An international health problem. International Journal of Gynecology and Obstetrics, 46, 155-163. 
Seligman, M. E. P. (2002). Authentic happiness: Using the new positive psychology to realize your potential for lasting fulfillment. New York: Free Press.

Sherbourne, C. D., \& Stewart, A. L. (1991). The MOS social support survey. Social Science \& Medicine, 32, 705-714.

Stewart, S. (2002). The effect of stepchildren on childbearing intentions and births. Demography, 39, 181-197.

Stones, M. J., \& Kuzma, A. (1986). "Happy are they who are happy..." A test between two causal models of happiness and its correlates. Experimental Aging Research, 12, 23-29.

Suh, E. M., Diener, E., \& Fujita, E. (1996). Events and subjective well-being: Only recent events matter. Journal of Personality and Social Psychology, 70, 1092-1102.

Thoits, P. A. (1999). Self, identity, stress, and mental health. Social Psychology Quarterly, 55, 236-256.

Thoits, P. A., \& Hewitt, L. N. (2001). Volunteer work and well-being. Journal of Health and Social Behavior, 42, 115-131.

Thornton, A., \& Young-DeMarco, L. (2000). Four decades of trends in attitudes toward family issues in the United States: The 1960s through the 1990s. Journal of Marriage and Family, 62, 1009-1038.

Veenhoven, R. (1994). Is happiness a trait? Social Indicators Research, 32, 101-160.

Wallston, K. A., Wallston, B. S., \& DeVellis, R. (1978). Development of the multidimensional health locus of control (MHLC) scales. Health Education Monographs, 6, 160-170.

White, J. M., \& Kline, D. M. (2002). Family theories (2nd ed.). Thousand Oaks, CA: Sage.

White, L., McQuillan, J., Greil, A. L., \& Johnson, D. R. (2006). Infertility: Testing a Help-seeking model. Social Science \& Medicine, 62(4), 1031-1041.

Wright, J., Allard, M., Lecours, A., \& Sabourin, S. (1989). Psychosocial distress and infertility: A review of controlled research. International Journal of Fertility, 34, 126-142.

Zhang, Z., \& Hayward, M. D. (2001). Childlessness and the psychological well-being of older persons. Journals of Gerontology B: Psychological Sciences and Social Sciences, 56, $311-320$. 